\title{
Contratações sustentáveis na administração pública brasileira: a experiência do Poder Executivo federal
}

\author{
Maria Alice Cruz Alencastro \\ Universidade Federal do Ceará (UFC) \\ Edson Vicente da Silva \\ Universidade Federal do Ceará (UFC) \\ Ana Maria D'Ávila Lopes \\ Universidade de Fortaleza (Unifor)
}

\begin{abstract}
A ampliação dos debates sobre os impactos ambientais decorrentes dos padrões de consumo da sociedade industrial levou à percepção do Estado como um expressivo consumidor de bens e serviços. Nesse sentido, diversos países passaram a adotar diretrizes e metodologias para inserir critérios de sustentabilidade em suas licitações, prática que ficou conhecida como contratação pública sustentável (CPS). Assim, este estudo objetiva analisar a implementação da CPS no âmbito do Poder Executivo federal brasileiro, considerando os objetivos que orientam esse processo, as normas de cumprimento obrigatório, suas potencialidades e limitações.
\end{abstract}

PALAVRAs-chavE: contratação pública sustentável; licitação sustentável; administração pública federal.

Contrataciones sostenibles en la administración pública brasileña: la experiencia del Poder Ejecutivo federal

La ampliación de los debates acerca de los impactos ambientales decurrentes de los patrones de consumo de la sociedad industrial llevó a la percepción del Estado como un expresivo consumidor de bienes y servicios. En ese sentido, diversos países pasaron a adoptar directrices y metodologías para incluir criterios de sustentabilidad en sus licitaciones, práctica que se hizo conocida como contratación pública sostenible (CPS). Así, este estudio objetiva analizar la implementación de la CPS en el ámbito del Poder Ejecutivo federal brasileño, considerando los objetivos que orientan ese proceso, las normas de cumplimiento obligatorio, sus potencialidades y sus limitaciones.

Palabras Clave: contratación pública sostenible; licitación sostenible; administración pública federal.

Artigo recebido em 16 nov. 2012 e aceito em 4 out. 2013. 
Sustainable procurements in the Brazilian public administration: the federal Executive Power's experience

The expansion of debates on the environmental impacts deriving from consumption patterns of the industrial society has led to the perception of the State as an expressive consumer of goods and services. This way, many countries started adopting guidelines and methodologies to include sustainability criteria in their public tenders, a practice that became known as sustainable public procurement (SPP). Thus, this study aims to analyze the implementation of SPP in the domain of the Brazilian federal Executive Power, taking into account the objectives that guide this process, the mandatory rules, its potentials and limitations.

KEYwORDs: sustainable public procurement; sustainable public tender; federal public administration.

\section{Introdução}

A sociedade contemporânea é marcada por uma situação paradoxal na exploração dos recursos naturais, uma vez que, ao mesmo tempo que os indivíduos desejam consumir todo tipo de produto e em uma quantidade sempre crescente, não assumem a responsabilidade das consequências negativas desse comportamento. Ou seja, a sociedade deseja e reivindica um meio ambiente ecologicamente equilibrado, mas não se conscientiza de que a garantia desse direito também depende das suas próprias ações.

Os atuais padrões de consumo derivam do desenvolvimento industrial e tecnológico que possibilitam a oferta de bens e serviços em larga escala. Cortez e Ortigoza (2007) fazem referência aos efeitos dos hábitos de consumo das sociedades ocidentais modernas, utilizando a expressão "era do descartável" para se referir à crescente produção de resíduos, fruto de uma "cultura do desperdício" e de padrões de consumo voltados para a aquisição de bens desnecessários e supérfluos.

De fato, diversos estudos (Veiga, 2005; Croxall et al., 2002; Esteller e Diaz-Delgado, 2002; Lambert, 2011; Cohen, 2003; Ozgul, 2010; Doney, 2010; Conti, 2011) enfatizam que o nível de exploração dos recursos naturais para a obtenção de matéria-prima se encontra em patamares muito superiores à capacidade de suporte dos ecossistemas. As mudanças climáticas, a poluição dos rios e mares, o desaparecimento de espécies da fauna e flora, dentre outros problemas, comprovam previsões que antes pareciam extremistas e distantes.

A partir da década de 1990 é possível observar uma mudança no enfoque das discussões relacionadas aos problemas ambientais, na medida em que os questionamentos acerca dos impactos causados pelos padrões de consumo ganharam espaço em detrimento das abordagens que levavam em consideração apenas os problemas relacionados com a atividade produtiva (Portilho e Russo, 2008).

Nesse contexto, surgem as expressões "consumo sustentável", "consumo consciente" ou "consumo responsável", para denominar o uso de bens e serviços para o atendimento das necessidades básicas e a melhoria da qualidade de vida humana, mas que, ao mesmo tempo, 
seja ambientalmente menos impactante, de forma a não comprometer o atendimento das necessidades das gerações futuras (Pnuma, 2001).

A compreensão de consumo sustentável parece materializar o próprio conceito de desenvolvimento sustentável consignado no Relatório de Brundtland, em 1987 (Pnuma, 2001). Nesse sentido, Cortez e Ortigoza (2007), analisando o conceito de consumo sustentável, destacam a necessidade de uma preocupação sistemática com a satisfação das necessidades da sociedade atual aliada à preservação dos recursos naturais, o que viabilizaria uma vida ambientalmente saudável para as gerações futuras.

No cenário internacional, a Agenda 21 Global registra, em seu capítulo 4, que "a principal causa da contínua deterioração do meio ambiente global são os padrões insustentáveis de produção e consumo", tendo conclamado as autoridades públicas a implementarem políticas e critérios de contratação capazes de favorecer a produção de bens e serviços ambientalmente sustentáveis (ONU, 1992).

Assim, se, inicialmente, a figura do consumidor foi precipuamente associada ao indivíduo, a ampliação do tema resultou na percepção de que as instituições, públicas e privadas, também são consumidoras expressivas de bens e serviços, podendo, em alguns casos, apresentar níveis de consumo bem mais significativos do que as pessoas físicas (Portilho e Russo, 2008).

Na Europa, os bens e serviços adquiridos pelos diversos órgãos da administração pública representam cerca de $19 \%$ do produto interno bruto da União Europeia (UE), o que corresponde à metade do Produto Interno Bruto (PIB) da Alemanha. Já no Brasil, as compras governamentais movimentam cerca de 10\% do PIB brasileiro (MPOG e Iclei, 2009).

Evidencia-se, assim, a importância dos atores governamentais como consumidores de produtos e serviços, o que tem estimulado diversos países a construir guias e planos de ação visando a implantação de mecanismos de gestão ambiental nos órgãos públicos. Dentro dessa perspectiva inserem-se as denominadas contratações públicas sustentáveis (CPS) ou licitações sustentáveis, como são conhecidas no Brasil.

As CPS têm sido apontadas como um relevante instrumento de gestão ambiental nos órgãos governamentais, haja vista objetivarem inserir critérios de sustentabilidade nos procedimentos destinados a adquirir bens e contratar serviços, além de estimular os governos a adotarem comportamentos que usualmente são exigidos de particulares e de pessoas jurídicas de direito privado, melhorando a imagem da autoridade pública. As CPS possuem, ainda, a capacidade de estimular o mercado "verde", levando empresas a inserirem práticas sustentáveis nos seus processos produtivos, visando à chancela de selos, rotulagens e certificações "verdes".

A maioria dos países desenvolvidos já instituiu procedimentos e instrumentos voltados para a implementação das CPS, dando ênfase especial aos aspectos ambientais através da aquisição de materiais reciclados, de materiais cujo processo de fabricação leve em conta critérios de sustentabilidade, de produtos que promovem menor consumo de energia, dentre outros. Áustria, Dinamarca, Finlândia, Alemanha, Holanda, Suécia e Reino Unido foram caracterizados, em 2007, como países "profundamente verdes" em termos de contratações públicas (Stevens, 2010). 
No Brasil já são registradas algumas ações no sentido de constituir um sistema de CPS. Nesse sentido, citam-se a publicação da quinta edição da Agenda Ambiental na Administração Pública A3P, em 2009, na qual foi inserido um eixo temático específico sobre licitações sustentáveis; a elaboração de um Guia de Compras Sustentáveis pelo Ministério do Planejamento, Orçamento e Gestão (MPOG); a expedição da Instrução Normativa (IN) no 1 , de 19 de janeiro de 2010, dispondo sobre os critérios de sustentabilidade ambiental na aquisição de bens, contratação de serviços ou obras pela administração pública federal direta, autárquica e fundacional; e a construção, desde 2007, do denominado Plano de Ação para Produção e Consumo Sustentáveis (PPCS), que consiste em uma política pública alinhada às ações do Processo de Marrakech, visando fomentar no Brasil a adoção de padrões de produção e consumo sustentáveis.

Além dessas ações, o governo federal, através da Secretaria de Logística e Tecnologia da Informação do MPOG, desenvolveu um sistema de compras informatizado com um catálogo de produtos sustentáveis. Tal catálogo pode ser utilizado pelos diversos órgãos como referência para a inclusão de critérios de sustentabilidade nas especificações dos bens e serviços dos editais de licitação.

Apesar da relevância e das repercussões políticas, econômicas e sociais dessas ações, constata-se a inexistência de estudos científicos sobre os impactos, limites e potencialidades da inserção de critérios de sustentabilidade nas contratações públicas brasileiras enquanto instrumento de política pública ambiental, bem como sobre a possibilidade de identificar as efetivas contribuições dessa prática a partir da mudança dos hábitos de consumo dos órgãos públicos.

Nesse contexto, o objetivo principal do presente estudo é realizar uma análise da implementação das CPS no âmbito do Poder Executivo federal brasileiro, considerando os objetivos que orientam esse processo, as normas de cumprimento obrigatório, suas potencialidades e limitações.

\section{0 papel do Estado como consumidor e as contratações públicas sustentáveis}

O debate sobre os impactos ambientais decorrentes dos padrões de consumo da sociedade industrial não caminhou no mesmo ritmo da emergência do discurso ambiental, só tendo ganhado destaque a partir da década de 1990, quando ocorreu um deslocamento discursivo da questão ambiental. Assim, o debate, antes voltado para os problemas ambientais relacionados à produção, passou a considerar os impactos ambientais decorrentes dos hábitos de consumo (Portilho e Russo, 2008).

A percepção da relação existente entre o consumo de produtos e serviços e o impacto do uso dos recursos naturais nos processos produtivos é apontada por Portilho e Russo (2008) como reflexo de um processo mais amplo de "ambientalização", em que diversos segmentos da sociedade incorporaram e ressignificaram o ideário ambientalista. 
Assim, os problemas ambientais decorrentes da sobre-exploração dos recursos naturais impulsionaram os debates sobre os padrões de consumo, resultando no nascimento de expressões como "consumo verde" e "consumo sustentável".

Segundo Portilho e Russo (2008), a expressão consumo verde possui caráter menos abrangente, restando inserida na concepção de consumo sustentável, uma vez que diz respeito apenas aos critérios de sustentabilidade ambiental considerados na escolha de produtos cujo processo de fabricação leve em consideração a eliminação ou a redução dos impactos causados ao meio ambiente.

A partir da proposta apresentada no Simpósio de Oslo sobre Produção e Consumo Sustentável, em 1994, adotada pela terceira sessão da Comissão para Desenvolvimento Sustentável (CDS III), em 1995, a expressão consumo sustentável foi definida como

o uso de bens e serviços que respondem às necessidades básicas e proporcionam uma melhor qualidade de vida, e ao mesmo tempo minimizam o uso de recursos naturais, materiais tóxicos e emissão de rejeitos e poluentes em seu ciclo de vida, de forma a não comprometer as necessidades das gerações futuras. (Pnuma, 2001:5)

Portanto, os níveis de consumo são sustentáveis quando são capazes de promover a satisfação das necessidades básicas, o desenvolvimento dos potenciais humanos e podem ser replicados por todo o planeta sem comprometer a capacidade de suporte dos ecossistemas (Marx, Paula e Sum, 2010).

No documento intitulado Rumo ao consumo sustentável na América latina e Caribe, o Programa das Nações Unidas para o Meio Ambiente (Pnuma) aborda a estreita vinculação entre as expressões consumo sustentável e desenvolvimento sustentável, fazendo referência à difusão formal desta última com o advento do Relatório de Brundtland, em 1987 (Pnuma, 2001).

Câmara (2009) ressalta que ao termo desenvolvimento sustentável pode ser atribuído o status de "palavra-chave" do final do século XX, apesar da confusão decorrente das numerosas definições que surgiram tentando definir sua exata compreensão.

Visando contribuir com o debate e destacar o processo de formação dessa expressão, Veiga (2005) promove uma fragmentação do vocábulo desenvolvimento sustentável para, então, analisar seu significado. Nesse sentido, o autor afirma que a expressão "desenvolvimento" passou a ser utilizada em oposição ao modelo de crescimento econômico consolidado a partir da Revolução Industrial, voltado apenas para o aumento da produtividade e da renda per capita, sem considerar outros fatores como os de ordem social e ambiental. Assim, Veiga (2005) caracteriza o "desenvolvimento", em sentido amplo, como uma mudança qualitativa significativa, que geralmente acontece de forma cumulativa.

No contexto histórico em que surgiu, a ideia de desenvolvimento implica a expiação e a reparação de desigualdades passadas, criando uma conexão capaz de preencher o abismo civilizatório entre as antigas nações metropolitanas e sua antiga periferia colonial, entre as minorias ricas modernizadas e a maioria ainda atrasada e exausta dos trabalhados pobres. O desenvolvimento 
traz consigo a promessa de tudo — a modernidade inclusiva propiciada pela mudança estrutural. (Sachs, 2008:15)

De acordo com os Relatórios do Desenvolvimento Humano publicados pelo Pnud desde 1990, o "desenvolvimento" tem sido conceituado como o alargamento das liberdades e capacidades das pessoas para viverem o tipo de vida que escolherem. Esse conceito vai além do simples atendimento das necessidades básicas, considerando que o desenvolvimento deve contribuir para que as pessoas tenham possibilidade de ter acesso àquilo que consideram relevantes para sua qualidade de vida (Pnud, 2011).

Por sua vez, a expressão "sustentável", como qualificativo que passou a ser utilizado para o conceito de "desenvolvimento", decorreu, segundo Veiga (2005), da percepção acerca do crescente esgotamento dos recursos naturais.

A expressão desenvolvimento sustentável foi publicamente utilizada pela primeira vez em agosto de 1979, no Simpósio das Nações Unidas sobre as Inter-relações entre Recursos, Ambiente e Desenvolvimento, realizado em Estocolmo, onde foi apresentado um texto intitulado A busca de padrões sustentáveis de desenvolvimento (Veiga, 2005).

No entanto, foram os eventos ambientais globais que culminaram na realização da Conferência das Nações Unidas sobre Meio Ambiente Humano, ocorrida em junho de 1972, em Estocolmo, na Suécia - com a participação de 113 países, 250 organizações não governamentais e organismos da ONU, que forneceram as bases para o processo de legitimação e institucionalização normativa da expressão "desenvolvimento sustentável”. Apesar da década de 1970 ter sido palco para outros eventos de cunho ambiental, a Conferência de Estocolmo passou a figurar como um divisor de águas para o despertar da consciência ambiental global e para o advento de um novo paradigma.

Como consequência da Conferência de Estocolmo, foi criado o Programa das Nações Unidas para o Meio Ambiente (Pnuma) — estabelecido em 1972 como agência do Sistema da ONU relacionada com proteção ambiental na perspectiva do desenvolvimento sustentável (Pnud, 2011).

Em 1983, o Pnuma criou a Comissão Mundial sobre Meio Ambiente e Desenvolvimento (CMMAD), que ficou mundialmente conhecida como Comissão de Brundtland, por ter sido presidida pela primeira-ministra da Noruega, Gro Harlem Brundtland. A comissão concluiu suas atividades em 1987 e apresentou suas conclusões acerca da situação ambiental do planeta, consignando os problemas socioeconômicos e ecológicos mundiais através do relatório denominado Nosso futuro comum.

Apesar de ter sido decorrência das preocupações expostas na Conferência de Estocolmo, o conceito de desenvolvimento sustentável foi formalmente reconhecido com o advento do Relatório de Brundtland que propôs o desenvolvimento sustentável “(...) como um processo de mudança onde a exploração de recursos, os investimentos e o desenvolvimento, deveriam estar vinculados às necessidades das gerações atuais e futuras" (Siena, 2002:30).

O Relatório Nosso futuro comum veio a conceituar o desenvolvimento sustentável nos seguintes termos: 
Desenvolvimento sustentável é um novo tipo de desenvolvimento capaz de manter o progresso humano não apenas em alguns lugares e por alguns anos, mas em todo o planeta e até um futuro longínquo;

(...)

O desenvolvimento sustentável é aquele que atende às necessidades do presente sem comprometer a capacidade de as gerações futuras atenderem as suas próprias necessidades.

(...)

Em essência, o desenvolvimento sustentável é um processo de transformação no qual a exploração dos recursos, a direção dos investimentos, a orientação do desenvolvimento tecnológico e a mudança institucional se harmonizam e reforçam o potencial presente e futuro, a fim de atender às necessidades e aspirações humanas (Comissão Mundial, 1991:4, 46, 49).

No cenário internacional, o conceito de desenvolvimento sustentável e a percepção acerca das consequências ambientais decorrentes dos hábitos de consumo só alcançaram difusão mundial a partir da realização da Conferência das Nações Unidas sobre o Meio Ambiente e o Desenvolvimento (Cnumad), na cidade do Rio de Janeiro, em 1992. Nesse evento foi produzida a Agenda 21 Global, um documento de 40 capítulos que não possui a obrigatoriedade comum aos tratados internacionais, mas que passou a ser considerado um dos principais instrumentos em matéria de políticas internacionais de gestão ambiental (Floriano, 2007).

O capítulo 4 da Agenda 21 Global destaca a importância do papel desempenhado pelos governos como consumidores, especialmente nos países onde o setor público possui uma posição preponderante na economia, podendo exercer considerável influência sobre decisões empresariais e sobre as opiniões da população. Nesse contexto, o documento enfatiza o dever de cada Estado de examinar as políticas de aquisição de bens e serviços de suas agências, órgãos e departamentos (ONU, 1992).

Palmujoki, Parikka-Alhola e Ekroos (2010) abordam a atenção que o setor público passou a receber nos últimos anos, considerando seu perfil de grande consumidor de bens e serviços. Os autores afirmam que é papel das autoridades públicas atuar como líderes no processo de mudança dos padrões de consumo.

Os órgãos públicos são os maiores consumidores na Europa, com um gasto em bens e serviços de, aproximadamente, 2 trilhões de euros por ano, o que equivale a 19\% do PIB europeu (Comissão Europeia, 2011). Brammer e Walker (2011) estimam que entre 8 e 25\% do Produto Interno Bruto (PIB) dos países-membros da Organização para a Cooperação e Desenvolvimento Econômico (Ocde) é atribuído às aquisições governamentais de bens e serviços.

Tais números evidenciam um grande potencial do setor público para estimular melhorias ambientais nos produtos disponibilizados no mercado, em inovações tecnológicas e em oportunidades para o desenvolvimento de um mercado de bens e serviços sustentáveis (Palmujoki, Parikka-Alhola e Ekroos, 2010).

Em um estudo sobre o papel da demanda do setor público na inovação no Canadá foram identificadas como áreas de maior influência: equipamentos ferroviários, equipamentos de telecomunicação, produtos farmacêuticos, aeronáutica, equipamentos elétricos industriais, 
mobiliário de escritório, construção naval e instrumentos científicos (Comissão Europeia, 2011).

Assim, considerando que os governos são, muitas vezes, os maiores compradores individuais de bens e serviços (Stevens, 2010), podem utilizar esse poder de compra para promoção do desenvolvimento sustentável em nível local, regional, nacional e internacional por meio das denominadas contratações públicas sustentáveis (CPSs) (Comissão Europeia, 2011).

As CPSs podem ser definidas como um processo no qual os órgãos governamentais procuram inserir critérios de sustentabilidade socioambiental nas práticas voltadas para a aquisição de bens e contratação de serviços. Portanto, constata-se que as CPSs dizem respeito à integração das preocupações com os impactos sociais e ambientais nas contratações realizadas pelos órgãos do setor público (Brammer e Walker, 2011).

Brammer e Walker (2011) relatam que as contratações públicas têm figurado no centro de recentes discussões sobre inovações políticas na seara ambiental, considerando a possibilidade de a demanda do Estado por bens e serviços servir como instrumento para estimular a sustentabilidade ambiental do setor industrial.

Nesse sentido, acredita-se que as CPS são capazes de estimular a inovação, fornecendo ao setor industrial incentivos concretos para o desenvolvimento e fornecimento de bens e serviços sustentáveis, considerando, especificamente, áreas onde a demanda do setor público representa uma expressiva parcela do mercado, como é o caso da construção de rodovias, dos serviços de saúde, transporte público, dentre outros (Comissão Europeia, 2011).

As aquisições públicas podem auxiliar na criação de um grande mercado para negócios sustentáveis, aumentando as margens de lucro dos produtores através de economias de escala, e reduzindo seus riscos. Por outro lado, as autoridades públicas, como consumidores de grande escala, podem incentivar a inovação, estimular a competição na indústria, garantindo, aos produtores, retornos pelo melhor desempenho ambiental de seus produtos, através da demanda do mercado ou de incentivos concretos (MPOG e Iclei, 2009:11).

Assim, as CPS passaram a ser vistas como um relevante instrumento de gestão ambiental passível de ser adotado pelos órgãos públicos, capaz de evidenciar a boa conduta governamental e de estimular a produção de bens ambientalmente menos impactantes (MPOG e Iclei, 2009).

A inserção de critérios de sustentabilidade nas contratações públicas também pode contribuir para o alcance de metas estabelecidas em políticas públicas ambientais e para o cumprimento de ações pactuadas em tratados e acordos internacionais relativos à garantia dos direitos humanos e à proteção dos recursos naturais (Comissão Europeia, 2011).

Apesar das experiências de países como Áustria, Dinamarca, Finlândia, Alemanha, Holanda, Suécia, Reino Unido e Canadá na implementação das CPS, somente a partir da década passada as contratações públicas passaram a ser objeto de pesquisas acadêmicas de forma mais significativa (Murray, 2009). 
Tais pesquisas evidenciam duas tendências na inserção de critérios de sustentabilidade nas contratações públicas: uma que considera apenas os critérios de sustentabilidade ambiental, e que ficou conhecida como contratação pública "verde" (CPV), e uma segunda corrente que objetiva conjugar os aspectos ambientais e sociais nas contratações públicas, e que restou denominada contratação sustentável.

Brammer e Walker (2011) ressaltam que existem poucos estudos abordando o alcance de objetivos sociais e ambientais, como resultado direto das contratações públicas, mencionando, nesse contexto, uma pesquisa desenvolvida na Irlanda do Norte sobre os impactos de um projeto voltado para a utilização das CPS na melhoria das taxas de desemprego da região.

No mesmo sentido, Stevens (2010) afirma que poucos países possuem práticas de CPS que levem em consideração aspectos sociais, como direitos humanos e condições de trabalho. O autor destaca o caso da Bélgica, que tem adotado o uso de uma etiqueta social na celebração de contratos públicos, a qual indica a conformidade com as convenções da OIT relativas a condições de trabalho, salários, liberdade de filiação sindical e não discriminação.

A maioria das pesquisas sobre CPS tem se debruçado sobre estudos de caso, examinando iniciativas principalmente nas das áreas da construção, tecnologia da informação, alimentação, madeira e produtos florestais (Brammer e Walker, 2011). Alguns trabalhos têm abordado, especificamente, as ferramentas para auxiliar na implementação das políticas de CPS, tendo evidenciado os estímulos decorrentes da legislação — considerando a aceitação de critérios de sustentabilidade pelas normas que disciplinam as contratações governamentais -, do acesso a informações e da quebra de barreiras (Kunzlik, 2003).

Além disso, Marron (2003) ressalta que, apesar de figurarem como relevante instrumento para a promoção da sustentabilidade ambiental e influenciarem o desempenho econômico do governo, existem poucos dados quantitativos abordando os impactos decorrentes da implementação das CPS. Em decorrência disso, a maioria dos estudos voltados para a avaliação dos impactos das contratações sustentáveis ampara-se em dados de caráter qualitativo.

\subsection{Princípios, objetivos e implementação das contratações públicas sustentáveis}

As CPS estão amparadas em dois princípios fundamentais: obtenção do melhor valor e garantia de tratamento justo a todos os interessados (Comissão Europeia, 2011).

A Comissão Europeia (2011) compreende que a obtenção do melhor valor significa encontrar uma solução que contemple os requisitos estabelecidos para os bens e serviços demandados da forma mais vantajosa para a administração pública. Dessa forma, na perspectiva das CPSs, a obtenção do melhor valor não leva em consideração apenas o preço dos bens e serviços, englobando fatores como qualidade, eficiência, proteção ambiental, garantia dos direitos humanos e respeito às leis trabalhistas, dentre outros.

Palmujoki, Parikka-Alhola e Ekroos (2010) esclarecem que, se o órgão público utiliza como critério de adjudicação o menor valor apresentado nas propostas dos interessados, os critérios socioambientais podem ser inseridos como uma pré-qualificação ou podem ser previstos como requisitos obrigatórios a serem observados durante a execução do contrato. 
Acerca dos objetivos das CPS, Marron (2003) destaca que algumas dessas políticas objetivam corrigir deficiências já existentes nas práticas de contratações do governo que, muitas vezes, apresentam alto custo e baixa qualidade ambiental. As políticas que identificam e corrigem tais deficiências são denominadas políticas de "ganho-ganho", uma vez que conduzem à melhoria socioambiental e ao aumento da eficiência governamental.

Por sua vez, outras políticas de CPS estão voltadas estritamente para a inserção de critérios de sustentabilidade socioambiental, mesmo que tais medidas resultem em aumento dos custos das aquisições governamentais. Quando apresentam esse formato, as políticas de CPS são classificadas como de "ganho-perda" e demandam maior fiscalização como meio de assegurar que o aumento dos custos para o governo foi, de fato, justificado pelos benefícios socioambientais decorrentes da sua implementação (Marron, 2003).

Visando facilitar a compreensão dos principais fatores que influenciam o processo de implementação das CPS, Brammer e Walker (2011) promoveram a adaptação do modelo conceitual retratado no quadro 1 .

Quadro 1

Modelo conceitual dos fatores que influenciam a implementação da CPS

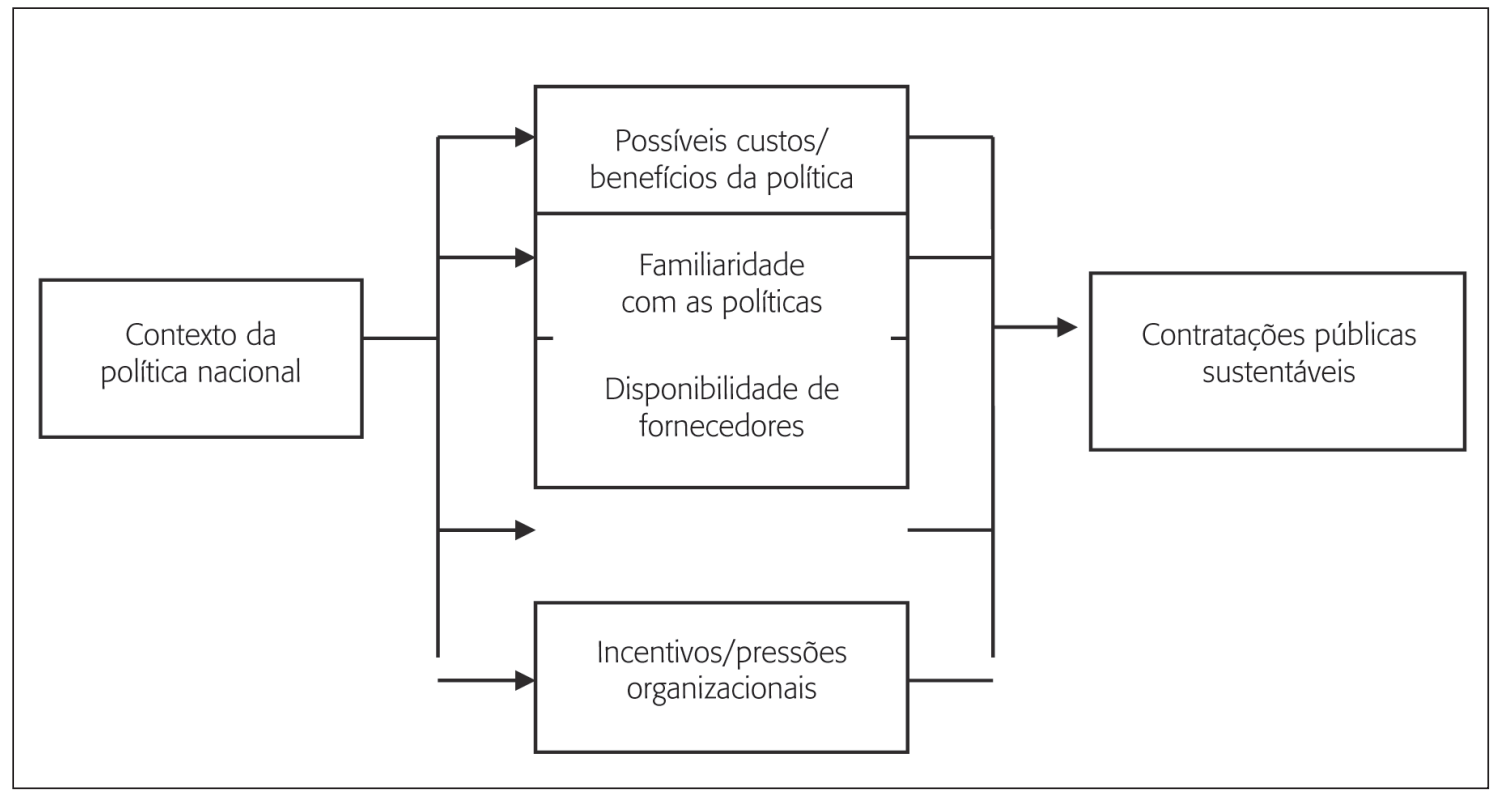

Fonte: Brammer e Walker (2011).

O modelo sugere que a implementação da CPS decorre, primordialmente, de pressões institucionais e é influenciada pelos seguintes fatores: custos e benefícios relativos à implantação das CPS; familiaridade com as CPS; disponibilidade de bens e serviços que considerem critérios de sustentabilidade; incentivos e pressões institucionais para implementação das CPS (Brammer e Walker, 2011). 
Acerca do primeiro fator, os autores esclarecem que, apesar de existirem diversos exemplos de situações vantajosas, tanto no campo financeiro como no socioambiental, a inserção de critérios de sustentabilidade é geralmente percebida como fator de elevação dos custos das contratações. Assim, os órgãos públicos estão mais propensos a considerar critérios de sustentabilidade em seus contratos quando percebem a existência de um custo-benefício positivo (Rao e Holt, 2005).

O segundo fator diz respeito à familiaridade com as CPS, pois, para que os órgãos possam implantar um sistema de contratações sustentáveis, torna-se essencial que os agentes que atuam nos setores responsáveis pelas contratações compreendam o conceito e objetivos das CPSs e das respectivas políticas governamentais. Nesse sentido, Brammer e Walker (2011:7) destacam que

a sustentabilidade já é, por si só, um conceito controvertido e complexo e os profissionais responsáveis pelas contratações podem não ter as habilidades e conhecimento necessários para a implementação exitosa das contratações sustentáveis. Os estudos desenvolvidos têm evidenciado que os gerentes de compras não têm certeza de como incorporar as dimensões éticas e sociais em suas compras.

O terceiro fator considera os efeitos da disponibilidade de bens e serviços produzidos de forma sustentável sobre as CPS, uma vez que, em muitas situações, a identificação de alternativas de fornecedores sustentáveis pode ser um grande obstáculo que interfere no processo de implementação das CPS (Brammer e Walker, 2011).

O último fator relaciona-se com os incentivos e as pressões institucionais para implementação das CPSs, inserindo-se nesse âmbito o nível de suporte fornecido pelas diretorias e centros de decisões da instituição, bem como o apoio decorrente dos processos e das estruturas organizacionais (Bansal e Roth, 2000).

De acordo com a Comissão Europeia (2011), a implementação de critérios de sustentabilidade nas contratações públicas demanda uma abordagem passo a passo. Uma dessas abordagens sugere a escolha de um pequeno grupo de produtos e serviços a serem inicialmente priorizados. Alguns fatores a serem considerados nessa escolha são as prioridades e particularidades das políticas públicas locais nos aspectos socioambientais, a disponibilidade de produtos no mercado e os custos envolvidos na aquisição de produtos sustentáveis, que devem considerar o valor de aquisição, os custos de utilização e descarte final.

Nesse sentido, a identificação de fontes de informações sobre bens e serviços sustentáveis é uma etapa essencial para a implementação das CPSs. A União Europeia tem desenvolvido critérios para um determinado grupo de produtos e serviços que são periodicamente revistos e atualizados. Os produtos e serviços atualmente abrangidos são: papel; produtos e serviços de limpeza; equipamentos de tecnologia da informação; construção; transporte; móveis; eletricidade; alimentos e serviços de hotelaria; produtos têxteis; celulares; janelas e portas de vidro e construção de estradas (Comissão Europeia, 2011). 
A falta de dados ambientais no que diz respeito à identificação e comparação da sustentabilidade de produtos e serviços é tipicamente considerada um dos maiores obstáculos para as CPSs. A complexidade e o custo das avaliações que consideram a análise do ciclo de vida do produto e a ausência de dados sobre aspectos sociais acabam restringindo as contratações sustentáveis a um número limitado de produtos e serviços.

Após a implantação de um sistema de contratações sustentáveis, a avaliação do progresso das ações nessa área dependerá, principalmente, de terem sido estabelecidas metas claras a serem alcançadas. Como exemplo, o órgão pode estipular um percentual de produtos sustentáveis ou de contratos que deverão incluir critérios de sustentabilidade. Entre as metas operacionais inserem-se também as ações de capacitação, em especial, dos profissionais que desenvolvem suas atividades nos setores de compras e contratos e a disponibilização de guias ou manuais sobre o tema para todo o corpo de funcionários.

Além do estabelecimento de metas objetivas a serem alcançadas, um fator de grande relevância para a efetividade das CPS é a expressividade quantitativa das aquisições governamentais. Marron (2003) enfatiza que as CPS serão um instrumento mais eficaz de política ambiental quando o setor público figurar como grande comprador de produtos relevantes, como ocorre com os setores da construção de rodovias e defesa, onde o governo é, em regra, o principal demandante. Uma implicação dessas constatações é que as CPS terão maior impacto em países que possuem estrutura governamental ampla e centralizada.

\section{As contratações públicas sustentáveis na administração pública federal brasileira}

No Brasil, os órgãos governamentais figuram como grandes consumidores de bens e serviços. No ano de 2009, o governo federal brasileiro gastou $\mathrm{R} \$ 11.530 .937 .746,36$ com obras e instalações, e R\$3.291.531.638,57 com equipamentos e material permanente (MPOG e Iclei, 2009). O Ipea (2011) aponta que o setor público se apresenta como um dos principais compradores do país, respondendo por cerca de $10 \%$ a $15 \%$ do PIB.

A implementação de uma política de CPS no Brasil tem origem nas metas estabelecidas na Agenda 21 Global, e também decorre da adesão do Brasil, no ano de 2007, ao Plano de Implementação de Joanesburgo.

Apesar das obrigações decorrentes dos documentos pactuados no cenário internacional, em decorrência do mandamento contido no inciso XXI do art. 37 da Constituição Federal de 1988, a aquisição de bens e a contratação de serviços pelos órgãos públicos brasileiros dependem da realização de prévio processo de licitação, ressalvados os casos especificados na legislação (Brasil, 1988). Essa obrigatoriedade aplica-se aos poderes Legislativo, Executivo e Judiciário da União, estados, Distrito Federal e municípios, incluídos os entes que integram a administração pública indireta.

Mota (2005:1) conceitua licitação como “o instrumento de que dispõe o Poder Público para coligir, analisar e avaliar comparativamente as ofertas, com a finalidade de julgá-las e decidir qual será a mais favorável". 
De acordo com Justen Filho (2012), no Brasil, a licitação obrigatória foi imposta por diversos diplomas legais ao longo do tempo, diferentemente da sistemática adotada por inúmeros outros Estados. O autor menciona que tal panorama acabou sendo modificado em decorrência da globalização, que impulsionou, em diversos países e no âmbito de organismos internacionais, ações voltadas para a adoção da obrigatoriedade de licitar.

A necessidade de incorporar critérios de sustentabilidade na condução dos processos licitatórios trouxe um novo desafio para o gestor público brasileiro que, historicamente, elaborou editais visando selecionar a proposta de menor valor, sem questionar as práticas socioambientais do fabricante ou do fornecedor dos bens e serviços.

A atuação do gestor, desvinculada de preocupações de ordem socioambiental, amparou-se, por sua vez, no teor da Lei n 8.666, de 21 de junho de 1993, que, até a alteração promovida pela Medida Provisória no 495, de 2010, convertida na Lei no 12.349 , de 15 de dezembro de 2010, apresentava a licitação como procedimento destinado a garantir a observância do princípio constitucional da isonomia e a garantir a proposta mais vantajosa para a administração pública (Brasil, 1993).

Antes mesmo de verificada a referida alteração na Lei no 8.666, de 1993, os que buscam evidenciar a relevância da implementação das CPSs no Brasil já defendiam a existência de amparo legal para sua prática, considerando o dever imposto ao Poder Público no art. 225 da Constituição Federal de 1988, bem como ante a previsão da defesa do meio ambiente dentre os princípios que regem a ordem econômica em seu art. 170. Além dos dispositivos constitucionais, o artigo 4 da Lei № 6.938, de 1981, já estabelecia, dentre os objetivos da Política Nacional do Meio Ambiente, a compatibilização do desenvolvimento socioeconômico com a preservação da qualidade do meio ambiente e do equilíbrio ecológico (Brasil, 1981).

No entanto, além da inexistência de previsão expressa na Lei no 8.666, de 1993, a implementação das CPS no Brasil também encontrava obstáculo nos questionamentos acerca da possibilidade de conciliar a inserção de critérios de sustentabilidade socioambiental com a garantia de tratamento isonômico a todos os interessados em contratar com a administração.

Por sua vez, posicionando-se dentre os que afastavam a tese de violação do princípio da igualdade, Barcessat (2011) entende que só seria vedado inserir critérios de sustentabilidade nos procedimentos licitatórios quando as exigências estabelecidas não guardassem consonância com o objeto e objetivos da licitação.

O Administrador Público, ao optar pelo objeto que venha a contribuir para um meio ambiente saudável, não estará ferindo o princípio da isonomia no momento da descrição do objeto, como, por exemplo, ao exigir que os móveis sejam de madeira certificada, material elétrico que tenha certificado de baixo consumo de energia, etc. Portanto, não há que se falar em violação do princípio da igualdade se as exigências constantes do edital estiverem afinadas com o objeto e objetivos da licitação, desde que respaldados pelos princípios prestigiados pelo legislador constitucional. Em síntese: os artigos 170 e 225 da CF/88, mesmo antes da mudança legislativa, já fundamentavam e respaldavam totalmente eventuais "fatores de discrímen" que viessem a ser 
erigidos para propiciar e respaldar a utilização, pela administração, de licitações sustentáveis na aquisição de bens e serviços (Barcessat, 2011:75).

Após a alteração promovida pela Lei $\mathrm{n}^{-}$12.349, de 2010, o art. $3^{\circ}$ a da Lei $\mathrm{n}^{\circ}$ 8.666, de 1993, passou a apresentar a seguinte redação:

Art. 3ํㅡㄹ A licitação destina-se a garantir a observância do princípio constitucional da isonomia, a seleção da proposta mais vantajosa para a administração e a promoção do desenvolvimento nacional sustentável e será processada e julgada em estrita conformidade com os princípios básicos da legalidade, da impessoalidade, da moralidade, da igualdade, da publicidade, da probidade administrativa, da vinculação ao instrumento convocatório, do julgamento objetivo e dos que lhes são correlatos. (Brasil, 2010)

Desta forma, a promoção do desenvolvimento sustentável nacional passou a ser expressamente prevista como um dos objetivos a serem obrigatoriamente considerados na realização do procedimento licitatório.

Assim, após a modificação da redação do art. 3ํ da Lei nº 8.666, de 1993, fica superada a discussão acerca da inexistência de amparo legal para inserção de critérios de sustentabilidade nos procedimentos licitatórios realizados pelos diversos órgãos da administração pública brasileira. Valente (2011:9) enfatiza que a referida modificação representa importante inovação legal e "(...) modifica radicalmente o quadro jurídico e operacional das licitações públicas no Brasil, obrigando todos os entes da Federação a promoverem licitações públicas sustentáveis".

Valente (2011) evidencia que a palavra "sustentável" não fazia parte da alteração do art. 3ํ da Lei no 8.666, de 1993, no texto da Medida Provisória no 495, de 2010, tendo sua inclusão ocorrido apenas durante a tramitação no Congresso Nacional.

Superados os principais obstáculos legais para a implementação das CPSs ou licitações sustentáveis, como têm sido denominadas no ordenamento jurídico brasileiro, resta transpor as barreiras que dificultam a conciliação da concepção de "proposta mais vantajosa" com "promoção do desenvolvimento nacional sustentável", considerando que os bens e serviços sustentáveis são vistos como possuidores de preços mais elevados.

Costa (2011) afirma que a proposta mais vantajosa não é, nem deveria ser interpretada como sinônimo de menor preço. Além disso, observa que, mesmo nos casos em que um produto sustentável demanda maior quantidade de recursos financeiros para ser adquirido, muitas vezes o custo de manutenção e de descarte são menores. "Se de fato fosse o desejo do legislador ordinário obrigar que a Administração Pública sempre contratasse pelo menor preço, isso estaria explícito na base legal que rege a matéria" (Costa, 2011:19).

A procura da proposta mais vantajosa para a Administração Pública deveria, portanto, ser desdobrada. Esta vantajosidade poderia manifestar-se no futuro, como ocorre nas licitações susten- 
táveis. Nestas os interesses primários e secundários da Administração Pública conjugar-se-iam. (Meneguzzi, 2011:25)

Mesmo diante da grande contribuição decorrente da alteração promovida pela Lei $\mathrm{n}^{-}$ 12.349, em dezembro de 2010, no âmbito do governo federal brasileiro, o status de primeiro marco regulatório para inserção de critérios de sustentabilidade nas contratações públicas é atribuído à Instrução Normativa (IN) no 1, de 19 de janeiro de 2010. Por meio da expedição da IN no 1 , o MPOG estabeleceu instruções a serem observadas na aquisição de bens, contratação de serviços ou obras pelos órgãos da administração pública federal direta, autárquica e fundacional (MPOG, 2010).

A IN nำ1, de 2010, estabelece em seu art. 1ํo que os editais licitatórios elaborados pelos órgãos e entidades da administração pública federal, para a aquisição de bens e contratação de serviços e obras, deverão conter critérios de sustentabilidade ambiental, considerando os processos de extração ou fabricação, utilização e descarte dos produtos e matérias-primas (MPOG, 2010).

Entretanto, destaca a IN que o cumprimento do disposto no art. 1ำ não deverá frustrar a competitividade, ou seja, torna-se necessário que as exigências ambientais a serem estabelecidas pelo órgão licitante não limitem a possibilidade de ampla participação das empresas interessadas que atendam os requisitos estabelecidos no edital.

Portanto, a IN objetiva orientar o gestor acerca dos possíveis critérios ambientais que podem ser utilizados no procedimento licitatório, cabendo ao órgão licitante inserir outros requisitos a serem atendidos de acordo com as especificidades institucionais. Apesar de privilegiar critérios voltados para a sustentabilidade ambiental, a IN também leva em consideração a busca do desenvolvimento local, prevendo que deve ser priorizado o emprego de mão de obra, materiais, tecnologias e matérias-primas de origem local para execução, conservação e operação das obras públicas (MPOG, 2010).

$\mathrm{Na}$ contratação de serviços, a IN sugere que o edital contenha critérios relacionados com a adoção de práticas sustentáveis pela empresa prestadora de serviços, dentre elas: que adote medidas para evitar o desperdício de água tratada; que forneça aos empregados os equipamentos de segurança que se fizerem necessários para a execução de serviços; que promova um programa interno de treinamento dos empregados para a redução do consumo de energia, de água e da produção de lixo; que realize a separação dos resíduos recicláveis descartados pelo órgão da administração contratante e promova sua destinação para associações ou cooperativas de catadores (MPOG, 2010).

Ao final, a IN institui a obrigação de os órgãos e entidades da administração pública federal, antes de realizarem a aquisição de novos bens, verificarem a disponibilidade de bens ociosos de outros órgãos que possam ser reutilizados.

Abordando os efeitos da IN, o Ipea (2011) destaca que as CPSs ampliam o conceito de contratação mais vantajosa nas licitações públicas, que passam a considerar a aquisição de produtos menos danosos ao meio ambiente e não apenas aqueles de menor preço. 
A vantagem está no fato de que os produtos sustentáveis são mais baratos no longo prazo — reduzem os gastos do Estado com políticas de reparação de danos ambientais, têm maior durabilidade, menor consumo de energia e materiais, e incentivam o surgimento de novos mercados e empregos verdes, gerando renda e aumento de arrecadação tributária (Ipea, 2011:17).

Por sua vez, Santos (2011) pondera a necessidade de a administração pública adotar medidas prévias voltadas para a ampliação do número de fornecedores de bens e serviços aptos a atender aos novos critérios estabelecidos pelas CPSs, sob pena de restar prejudicado o princípio da isonomia.

Considere à guisa de exemplo a seguinte situação hipotética: suponha que um órgão deseja adquirir uma grande quantidade dos chamados computadores verdes, sendo que uma única empresa está preparada para fornecer o equipamento. Diante desta situação restará prejudicado o princípio da isonomia, visto que não há diversos licitantes em igual condição de competição. Logo, cabe à Administração Pública realizar audiências públicas, congressos, seminários, entre outros, para que possa apresentar aos licitantes suas futuras aquisições, fazendo com que o mercado possa preparar para fornecer a nova leva de produtos e serviços ecologicamente corretos que o poder público visa adquirir (Santos, 2010:2).

Entretanto, a compreensão das dificuldades efetivamente enfrentadas pela administração pública brasileira para inserir critérios de sustentabilidade nas compras dos bens necessários ao seu funcionamento não está restrita ao perfil dos produtores ou às condições atuais do mercado, demandando uma análise aprofundada do desenvolvimento desse processo no Brasil.

\section{Procedimentos metodológicos}

Para possibilitar o alcance dos objetivos estabelecidos no presente estudo, foram analisadas as ações adotadas pelos órgãos centrais do Poder Executivo federal brasileiro.

Assim, foram consideradas as práticas adotadas pelos ministérios, na condição de órgãos que integram a cúpula administrativa do Poder Executivo, responsáveis pela formulação, implantação e acompanhamento das políticas públicas em nível federal, possuindo, ainda, autonomia técnica, financeira e administrativa para executar as ações em suas áreas de competência.

Os ministérios encontram-se diretamente subordinados ao presidente da República, auxiliando no exercício do Poder Executivo federal. Também possuem como atribuição o estabelecimento de estratégias, diretrizes e prioridades na aplicação de recursos públicos, a criação de normas e o acompanhamento e avaliação de programas federais. Além disso, compete a cada ministério a coordenação e supervisão dos órgãos e entidades da administração federal na sua área de atuação. 


\subsection{Técnicas da pesquisa}

Quanto às fontes utilizadas, a pesquisa bibliográfica abrangeu livros, artigos, periódicos, publicações avulsas e dados disponíveis na rede mundial de computadores - internet.

Os dados secundários foram obtidos, em especial, a partir das informações constantes no Sistema Comprasnet e no Portal da Transparência, sítio gerenciado pela Controladoria Geral da União (CGU).

\subsection{Operacionalização da coleta de dados}

Considerando a impossibilidade de analisar os impactos dos procedimentos licitatórios realizados por todos os órgãos que fazem parte da estrutura do Poder Executivo federal, promoveu-se a utilização da amostragem probabilística.

O total de 26 ministérios foi considerado a população a partir da qual foi obtido um subconjunto fazendo uso do processo de amostragem aleatória. Assim, utilizando-se um nível de confiança de $95 \%$ e um erro máximo de 3 pontos percentuais, a aplicação da fórmula seguinte resultou em uma amostra de 12 ministérios (Fonseca e Martins, 1996).

$$
n=\frac{\sigma^{2} p \cdot q \cdot N}{e 2(N-1)+\sigma^{2} p \cdot q}
$$

Onde:

$\mathrm{n}=$ tamanho da amostra;

$\sigma=$ abscissa da normal padrão (nível de confiança escolhido);

$\mathrm{p}=\%$ com a qual o fenômeno se verifica;

$\mathrm{q}=$ percentagem complementar (100-p);

$\mathrm{e}=$ erro de amostragem;

$\mathrm{N}=$ tamanho da população $=$ número de ministérios

Após a obtenção da amostra, foi utilizado o método de sorteio, onde os elementos da população foram numerados de 1 a 26 e sorteados aleatoriamente, sem reposição, até que fosse atingido o quantitativo de 12 ministérios.

Concluído esse processo, a amostra restou composta pelos ministérios relacionados no quadro 2.

A análise da inserção de critérios de sustentabilidade nos procedimentos licitatórios realizados pelos órgãos integrantes da amostra foi efetuada considerando os aspectos sociais, econômicos e ambientais presentes nos procedimentos realizados através do Sistema Comprasnet. 
Quadro 2

\section{Ministérios integrantes da amostra}

1. Ministério da Fazenda

2. Ministério da Educação

3. Ministério da Integração Nacional

4. Ministério da Previdência Social

5. Ministério das Comunicações

6. Ministério do Meio Ambiente

7. Ministério dos Transportes

8. Ministério do Planejamento, Orçamento e Gestão

9. Ministério da Cultura

10. Ministério da Justiça

11. Ministério da Saúde

12. Ministério do Desenvolvimento Agrário

Fonte: Pesquisa.

A pesquisa também compreendeu a análise dos mecanismos utilizados pela administração pública federal para especificação dos produtos sustentáveis adquiridos e as alternativas para inserção de critérios de sustentabilidade nessas aquisições, considerando a disponibilidade e a possibilidade de identificação de produtos "sustentáveis" no mercado.

\section{Resultados obtidos}

A política de CPS, instituída no Brasil em janeiro de 2010, está amparada na inserção de critérios de sustentabilidade no instrumento convocatório do procedimento licitatório, que não devem resultar no comprometimento da competitividade do certame.

Os critérios de sustentabilidade ambiental utilizados deverão considerar os processos de extração, fabricação, utilização e descarte dos produtos e matérias-primas.

De acordo com a IN oํ 1, de 2010, os critérios da política de CPS do Poder Executivo Federal brasileiro encontram-se divididos em dois grupos: obras públicas e bens e serviços.

Os critérios a serem observados nas obras ou serviços de engenharia são de cunho obrigatório e estão previstos no art. $4^{\circ}$ da IN, podendo ser agrupados conforme o quadro 3.

Constatou-se que praticamente todos os requisitos estabelecidos pela IN $n^{-}$, de 2010, para as obras e serviços de engenharia visam apenas a sustentabilidade ambiental. Nesse sentido, identificou-se a previsão de apenas um critério de cunho social, cujo cumprimento é classificado como voluntário, que visa estimular o emprego de mão de obra, materiais e matérias-primas de origem local para a execução, conservação e operação das obras públicas. 
Quadro 3

Critérios de sustentabilidade a serem considerados nas obras ou serviços de engenharia de acordo com o art. 4을 IN no 1, de 2010

\begin{tabular}{|c|c|}
\hline Natureza do critério & Incisos correspondentes \\
\hline Melhoria do aproveitamento da água & $\begin{array}{l}\text { V. sistema de medição individualizado de consumo de água e energia; } \\
\text { VI. sistema de reúso de água e de tratamento de efluentes gerados; } \\
\text { VII. aproveitamento da água da chuva, agregando ao sistema hidráulico } \\
\text { elementos que possibilitem captação, transporte, armazenamento e seu } \\
\text { aproveitamento; }\end{array}$ \\
\hline Melhoria do aproveitamento energético & $\begin{array}{l}\text { I. uso de equipamentos de climatização mecânica, ou de novas tecnologias } \\
\text { de resfriamento do ar, que utilizem energia elétrica, apenas nos ambientes } \\
\text { aonde for indispensável; II. automação da iluminação do prédio, projeto } \\
\text { de iluminação, interruptores, iluminação ambiental, iluminação tarefa, uso } \\
\text { de sensores de presença; III. uso exclusivo de lâmpadas fluorescentes } \\
\text { compactas ou tubulares de alto rendimento e de luminárias eficientes; IV. } \\
\text { energia solar, ou outra energia limpa para aquecimento de água; }\end{array}$ \\
\hline $\begin{array}{l}\text { Gestão de resíduos, reutilização e } \\
\text { biodegradabilidade }\end{array}$ & $\begin{array}{l}\text { VIII. utilização de materiais que sejam reciclados, reutilizados e biodegradáveis, } \\
\text { e que reduzam a necessidade de manutenção; }\end{array}$ \\
\hline Rastreabilidade & $\begin{array}{l}\text { IX. comprovação da origem da madeira a ser utilizada na execução da obra } \\
\text { ou serviço. }\end{array}$ \\
\hline
\end{tabular}

Fonte: Adaptado de MPOG (2012).

Por sua vez, os critérios estabelecidos para a contratação de outros serviços, que não se classifiquem como serviços de engenharia, também são de cumprimento obrigatório, prevendo: o uso de produtos de limpeza e conservação de superfícies e objetos inanimados que obedeçam às classificações e especificações determinadas pela Anvisa; a adoção de medidas para evitar o desperdício de água tratada, conforme instituído no Decreto ํㅡㄴ 48.138, de 8 de outubro de 2003; a observância da Resolução Conama no 20, de 7 de dezembro de 1994, quanto aos equipamentos de limpeza que gerem ruído no seu funcionamento; o fornecimento dos equipamentos de segurança que se fizerem necessários, para a execução de serviços; a realização de um programa interno de treinamento de seus empregados, nos três primeiros meses de execução contratual, para redução de consumo de energia elétrica, de consumo de água e redução de produção de resíduos sólidos, observadas as normas ambientais vigentes; a separação dos resíduos recicláveis descartados pelos órgãos e entidades da administração pública federal, na fonte geradora, e sua destinação às associações e cooperativas dos catadores de materiais recicláveis, que será procedida pela coleta seletiva do papel para reciclagem, quando couber, nos termos da IN/Mare no 6, de 3 de novembro de 1995 e do Decreto no 5.940, de 25 de outubro de 2006; destinação ambiental adequada das pilhas e baterias usadas ou inservíveis, segundo disposto na Resolução Conama no 257, de 30 de junho de 1999.

Além dos critérios expressamente previstos nas CPSs voltadas para a contratação de serviços, a IN também autoriza os órgãos a estabelecerem outros critérios de sustentabilidade ambiental, desde que justificadamente. 
No grupo das CPS referentes à compra de bens, todos os critérios são de cunho voluntário, ficando como decisão discricionária do gestor sua adoção. O quadro 4 apresenta o detalhamento desses critérios de acordo com o texto da IN oㅜ 1, de 2010.

\section{Quadro 4 \\ Critérios de sustentabilidade a serem considerados nas compras de bens de acordo com a IN no 1 , de 2010}

\begin{tabular}{|l|l|}
\hline Natureza do contrato & \multicolumn{1}{|c|}{ Critérios de sustentabilidade a serem observados } \\
\hline & I. que os bens sejam constituídos, no todo ou em parte, por material reciclado, \\
& atóxico, biodegradável, conforme ABNT NBR - 15448-1 e 15448-2; \\
& II. que sejam observados os requisitos ambientais para a obtenção de \\
& certificação do Instituto Nacional de Metrologia, Normalização e Qualidade \\
Industrial (Inmetro) como produtos sustentáveis ou de menor impacto & ambiental em relação aos seus similares; \\
III. que os bens devam ser, preferencialmente, acondicionados em embalagem \\
individual adequada, com o menor volume possível, que utilize materiais \\
recicláveis, de forma a garantir a máxima proteção durante o transporte e o \\
armazenamento; \\
IV. que os bens não contenham substâncias perigosas em concentração \\
acima da recomendada na diretiva RoHS (Restriction of Certain Hazardous \\
Substances), tais como mercúrio (Hg), chumbo (Pb), cromo hexavalente \\
(Cr(VI)), cádmio (Cd), bifenilpolibromados (PBBs), éteres difenil-polibromados \\
(PBDEs).
\end{tabular}

Fonte: Adaptado de MPOG (2012).

Segundo dados do MPOG (2012), desde janeiro de 2010, com advento da IN no 1 , a março de 2012, o governo federal brasileiro já realizou 1.490 licitações inserindo especificações de itens classificados como sustentáveis pelo Sistema Integrado de Administração de Serviços Gerais (Siasg).

Para suprir a demanda por fontes de informação sobre produtos sustentáveis, o MPOG desenvolveu uma plataforma voltada especificamente para as CPSs. A plataforma está vinculada ao sítio do Comprasnet e integrada ao sistema Siasg e disponibiliza a relação de todos os itens sustentáveis já cadastrados no catálogo de materiais (Catmat) do sistema de compras do governo federal.

Ao todo, o catálogo possui um total de 760 produtos classificados como sustentáveis e facilita o trabalho de identificação e discriminação de produtos sustentáveis nos editais de licitação. A tabela 1 apresenta as categorias e variedades de produtos classificados como sustentáveis com especificação cadastrada no Catmat. 
Tabela 1

\section{Categorias e variedades de produtos cadastrados no Catmat}

\begin{tabular}{|c|c|}
\hline Categoria do produto & Total de variedades cadastradas \\
\hline Agente espumante & 02 \\
\hline Alvejante de tecido & 03 \\
\hline Anticorrosivo & 03 \\
\hline Aparelho de ar-condicionado & 37 \\
\hline Bateria recarregável & 07 \\
\hline Bloco de recado/rascunho & 09 \\
\hline Broxa pintura & 01 \\
\hline Cabo audiofrequência & 01 \\
\hline Caderno & 01 \\
\hline Caixas & 18 \\
\hline Caneta esferográfica & 07 \\
\hline Capa processo & 02 \\
\hline Cartão e cartão de identificação & 02 \\
\hline Cartolina & 02 \\
\hline Cartucho (tinta e toner) & 292 \\
\hline Certificado & 02 \\
\hline Computador & 02 \\
\hline Copo descartável & 05 \\
\hline Detergentes & 31 \\
\hline Diploma & 01 \\
\hline Disjuntor & 07 \\
\hline Embalagem plástica & 03 \\
\hline Envelope & 35 \\
\hline Estojo para CD-ROM & 01 \\
\hline Etiqueta adesiva & 05 \\
\hline Fita enxertia & 02 \\
\hline Fogão a gás & 01 \\
\hline Formulário oficial/contínuo & 08 \\
\hline Frigobar & 05 \\
\hline Impressora & 21 \\
\hline Lâmpada & 04 \\
\hline Lápis & 01 \\
\hline Lapiseira & 02 \\
\hline Livro de ata & 01 \\
\hline Livro de protocolo & 01 \\
\hline
\end{tabular}




\begin{tabular}{|c|c|}
\hline Categoria do produto & Total de variedades cadastradas \\
\hline Lubrificante & 01 \\
\hline Microcomputador pessoal - notebook & 02 \\
\hline Pano de prato & 03 \\
\hline Papel A4 e A3 & 17 \\
\hline Papel flip chart & 03 \\
\hline Papel higiênico & 01 \\
\hline Papel ofsete & 32 \\
\hline Papel sulfite & 04 \\
\hline Papelão & 15 \\
\hline Pasta de limpeza & 02 \\
\hline Pasta para arquivo & 04 \\
\hline Pasta para eventos & 03 \\
\hline Pilha & 02 \\
\hline Plástico & 12 \\
\hline Porta-lápis/clipe/lembrete & 01 \\
\hline Protetor para assento sanitário & 03 \\
\hline Refrigerador & 04 \\
\hline Régua & 03 \\
\hline Removedor & 02 \\
\hline Sabão em pó e saponáceos & 11 \\
\hline Sabonete & 01 \\
\hline Saco plástico para lixo & 11 \\
\hline Solução de limpeza multiuso & 03 \\
\hline Televisor & 01 \\
\hline Toalha de papel & 02 \\
\hline Vassoura & 01 \\
\hline Veículo/automóvel & 50 \\
\hline
\end{tabular}

Fonte: Adaptado de MPOG (2012).

Constatou-se a inexistência de dados sobre os critérios sociais ou ambientais para servir de suporte para as CPSs que visam a contratação de serviços.

Acerca da demanda por produtos sustentáveis no período de janeiro de 2010 a julho de 2012, verificou-se que os produtos mais adquiridos são cartucho de tinta reciclado para impressora, toner reciclado para impressora, aparelhos de ar-condicionado e papel reciclado, conforme o gráfico1. 
Gráfico 1

Percentual dos produtos sustentáveis mais adquiridos no período de janeiro de 2010 a julho de 2012 através do Comprasnet

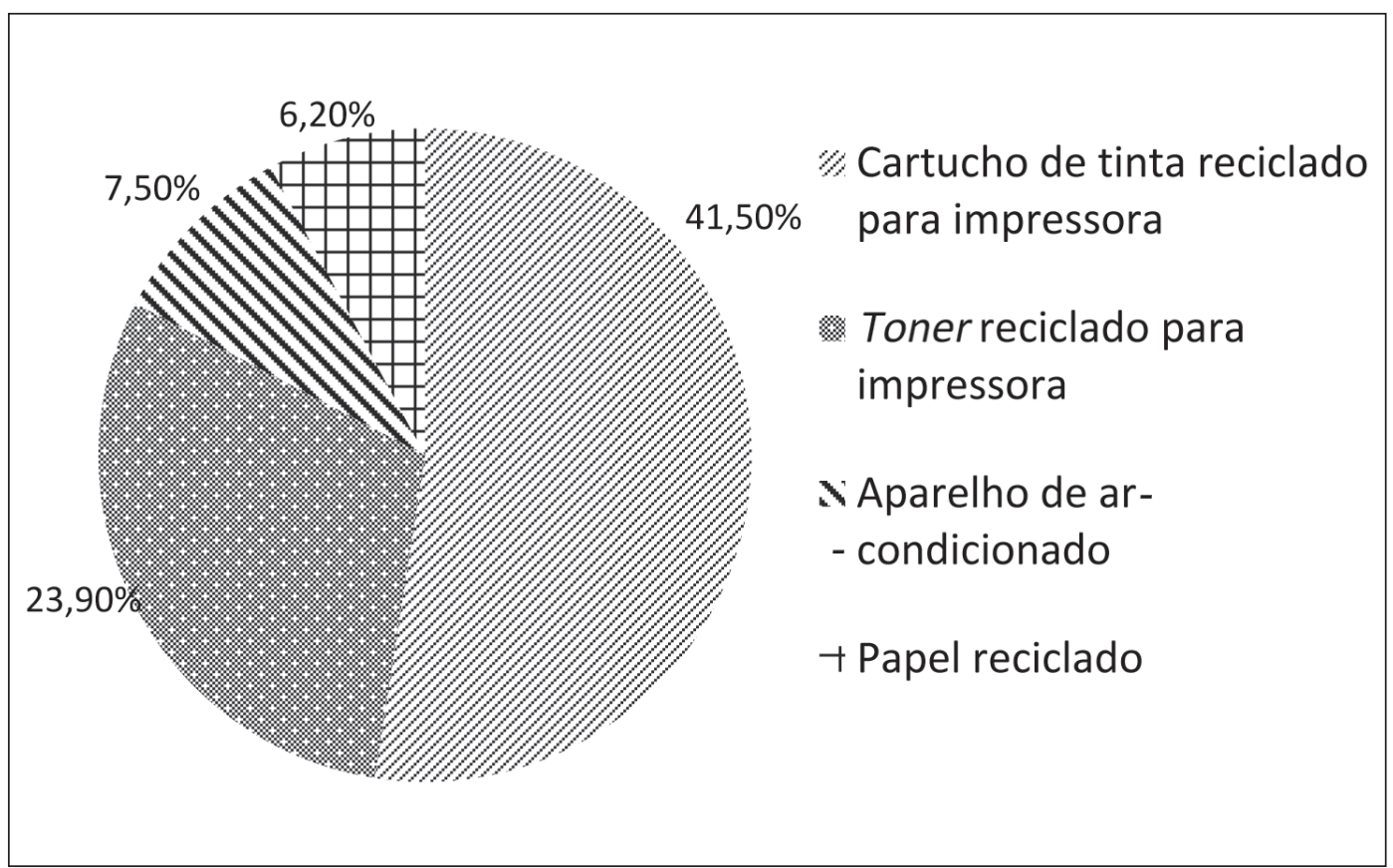

Fonte: MPOG (2012).

A análise dos dados revelou que entre janeiro de 2010 e julho de 2012 foram realizados 1507 procedimentos de compras sustentáveis, conforme distribuição especificada no gráfico 2. Os números apresentados consideraram os procedimentos realizados através dos órgãos centrais de cada ministério e por todos os órgãos a eles vinculados.

Os itens adquiridos nas CPSs realizadas pelos órgãos integrantes da amostra apresentaram a seguinte composição: cartucho toner reciclado; cartucho reciclado; aparelho de arcondicionado com selo Procel; papel reciclado (sulfite e A4); microcomputador notebook condicionais ROHS (TI verde); bateria recarregável; caixa de papelão reciclado; envelope para papel reciclado; pasta arquivo, suspensa, de papelão reciclado; lâmpada fluorescente; automóvel mínimo 1.6, bicombustível; almofada para carimbo em plástico reciclado; bloco para recado em papel reciclado; lapiseira em plástico reciclado e pasta para arquivo em polietileno reciclado. 
Gráfico 2

Número de licitações sustentáveis realizadas pelos órgãos integrantes da amostra no período de janeiro de 2010 a julho de 2012 por meio do Comprasnet

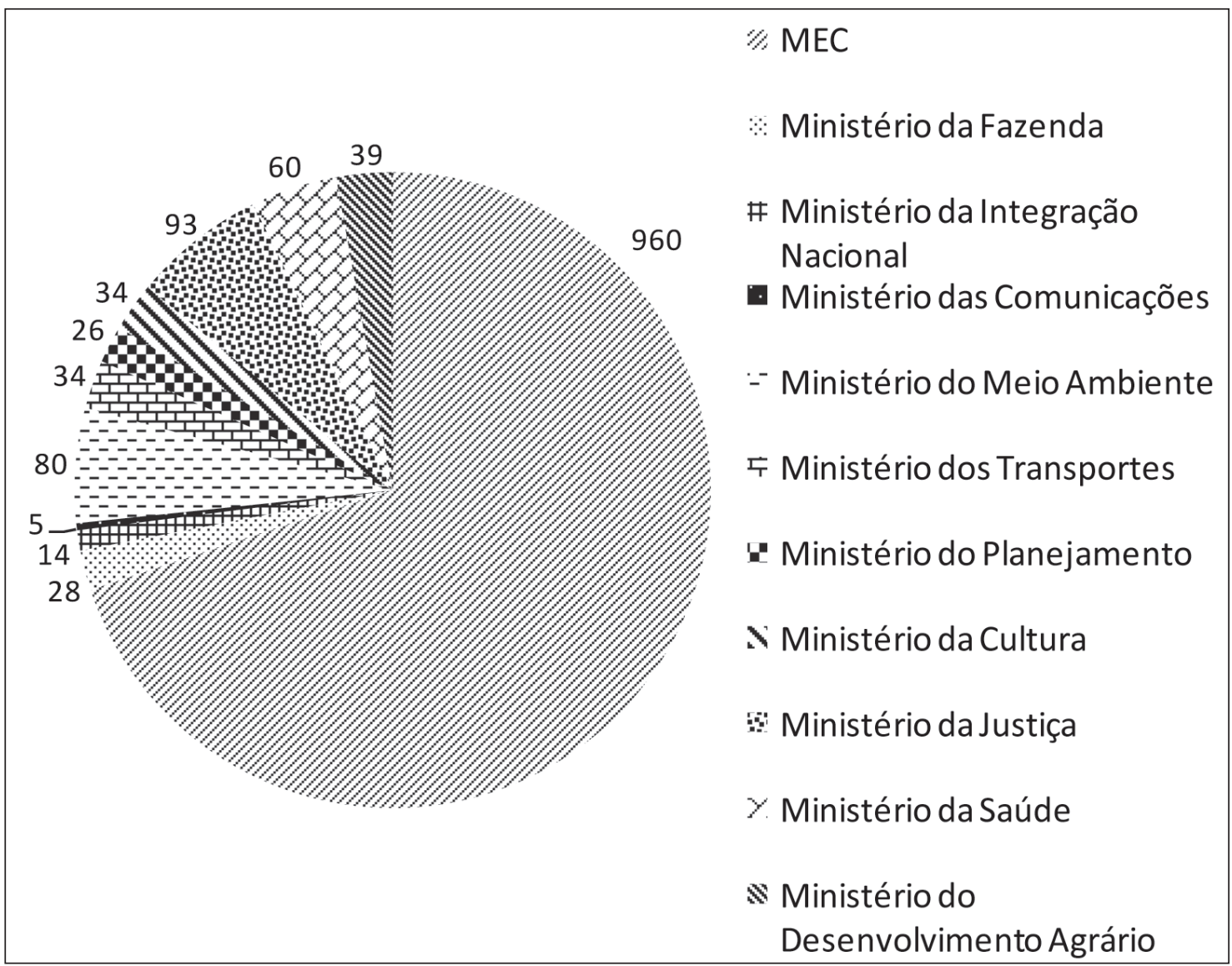

Fonte: MPOG (2012).

\section{Considerações finais}

A percepção do Estado como expressivo consumidor de bens e serviços fomentou o debate sobre os impactos e mecanismos capazes de promover a inserção de critérios de sustentabilidade nas contratações públicas. No Brasil, as CPSs foram estabelecidas na esfera federal em janeiro de 2010, visando, principalmente, o alinhamento com as metas estabelecidas no Processo de Marrakech.

O estudo considerou um recorte amostral a partir dos órgãos centrais do Poder Executivo federal, tendo evidenciado uma dissonância entre a compreensão conceitual das CPSs e os requisitos estabelecidos na Instrução Normativa ํo 1, de 2010, expedida pelo Ministério do Planejamento, Orçamento e Gestão, visando disciplinar a inserção de critérios de sustentabi- 
lidade nas contratações dos órgãos federais. Nesse sentido, a Instrução Normativa privilegia os critérios de caráter ambiental em detrimento dos aspectos sociais, que poderiam impactar positivamente os arranjos produtivos locais e o cumprimento das normas trabalhistas nos contratos de prestação de serviços.

A análise dos dados extraídos do sistema Comprasnet revelou que quase metade dos itens classificados como sustentáveis adquiridos no período de janeiro de 2010 a julho de 2012 é composta por um único produto: cartucho de tinta reciclado.

O estudo também evidenciou que categorias de produtos sustentáveis com especificações cadastradas no sistema Catmat possuem pouca ou nenhuma variedade, com exceção dos cartuchos de tinta e toner para impressora, com 292 tipos cadastrados.

As especificações dos produtos constantes no Catmat possuem um papel relevante para a implementação das licitações sustentáveis, uma vez que, considerando a inexistência de um "selo verde" padronizado pelo Inmetro, o uso das informações cadastradas no Catmat possibilita maior agilidade e segurança para os responsáveis pela realização dos procedimentos identificarem a adequada especificação para a aquisição de produtos considerados sustentáveis.

Acerca da efetividade das CPSs, considerando as contratações realizadas pelos órgãos integrantes da amostra no período de janeiro de 2010 a julho de 2012, observou-se que as licitações sustentáveis estão praticamente restritas ao Ministério da Educação e aos órgãos vinculados à estrutura desse ministério nos diversos estados da federação. Portanto, apesar do aumento no percentual de aquisições sustentáveis desde o início da vigência da Instrução Normativa no 1, em janeiro de 2010, o estudo revelou que mais da metade dos órgãos do Poder Executivo federal tem participação inexpressiva nesse processo, o que demanda atuação do MPOG no sentido de identificar e corrigir as causas desse problema.

\section{Referências}

BANSAL, Pratima; ROTH, Kendall. Why companies go green: a model of ecological responsiveness. Academy of Management Journal, v. 43, n. 4, p. 717-736, ago. 2000. Disponível em: <http://amj. aom.org/content/43/4/717.full.pdf+html>. Acesso em: 8 mar. 2012.

BARCESSAT, Lena. Papel do estado brasileiro na ordem econômica e na defesa do meio ambiente: necessidade de opção por contratações públicas sustentáveis. In: SANTOS, Murillo; BARKI, Teresa V. P. (Coord.). Licitações e contratações públicas sustentáveis. Belo Horizonte: Fórum, 2011. p. 67-80.

BRAMMER, Stephen; WALKER, Helen. Sustainable procurement in the public sector: an international Comparative study. International Journal of Operations \& Production Management, v. 31, n. 4, p. 452-476, abr./maio 2011. Disponível em: <www.emeraldinsight.com/products/journals/journals. htm?id=ijopm $>$. Acesso em: 8 mar. 2012.

BRASIL. Constituição da República Federativa do Brasil. Brasília, DF: Senado, 1988. 
BRASIL. Lei no 6.938, de 31 de agosto de 1981. Dispõe sobre a Política Nacional do Meio Ambiente, seus fins e mecanismos de formulação e aplicação, e dá outras providências. Diário Oficial [da] República Federativa do Brasil, Brasília, DF, 2 set. 1981. Disponível em: <www.planalto.gov.br/> . Acesso em: 6 out. 2012.

BRASIL. Lei no 8.666, de 21 de junho de 1993. Regulamenta o art. 37, inciso XXI, da Constituição Federal, institui normas para licitações e contratos da Administração Pública e dá outras providências. Diário Oficial [da] República Federativa do Brasil, Brasília, DF, 22 jun. 1993. Disponível em: <www.planalto.gov.br/>. Acesso em: 10 jun. 2013.

BRASIL. Lei no 12.349 , de 15 de dezembro de 2010. Altera as Leis nos 8.666, de 21 de junho de 1993, 8.958, de 20 de dezembro de 1994, e 10.973, de 2 de dezembro de 2004; e revoga o $\S 1$ o do art. $2^{\circ}$ da Lei ํㅜ 11.273, de 6 de fevereiro de 2006. Diário Oficial [da] República Federativa do Brasil, Brasília, DF, 16 dez. 2010. Disponível em: <www.planalto.gov.br/>. Acesso em: 10 jun. 2013.

CÂMARA, Renata P. B. Desenvolvimento sustentável. In: ALBUQUERQUE, José. L. (Org.). Gestão ambiental e responsabilidade social: conceitos, ferramentas e aplicações. São Paulo: Atlas, 2009. p. $70-87$.

CMMD. Comissão Mundial sobre o Meio Ambiente e Desenvolvimento. Nosso futuro comum. 2. ed. Rio de Janeiro: Fundação Getulio Vargas, 1991.

COHEN, Joel E. Human population: the next half century. Science, v. 302, n. 5648, p. 1172-1175, nov./dez. 2003. Disponível em: <www.sciencemag.org/content/302/5648/1172.abstract>. Acesso em: 12 mar. 2012.

COMISSÃO EUROPEIA. Buying green. A handbook on green public procurement. 2. ed. Luxemburgo: Publications Office of the European Union, 2011. Disponível em: <http://ec.europa.eu/environment/gpp/pdf/handbook.pdf>. Acesso em: 10 jan. 2012.

CONTI, Jose B. Clima e meio ambiente. São Paulo: Saraiva, 2011.

CORTEZ, Ana T. C.; ORTIGOZA, Silvia A. G. (Org.). Consumo sustentável: conflitos entre necessidade e desperdício. São Paulo: Unesp, 2007.

COSTA, Carlos E. L. As licitações sustentáveis na ótica do controle externo. Monografia (especialista em auditoria e controle governamental) — Instituto Serzedello Corrêa, Brasília, 2011.

CROXALL, John P. et al. Environmental change and Antarctic seabird populations. Science, v. 297, n. 5586, p. 1510-1514, ago. 2002. Disponível em: <www.sciencemag.org/content/297/5586/1510>. Acesso em: 3 nov. 2011.

DONEY, Scott C. The growing human footprint on coastal and open-ocean biogeochemistry. Science, v. 328, n. 5985, p. 1512-1516, jun. 2010. Disponível em: <www.sciencemag.org/ content/328/5985/1512 >. Acesso em: 12 mar. 2012.

ESTELLER, Maria V.; DIAZ-DELGADO, Carlos. Environmental effects of aquifer overexploitation: a case study in the highlands of Mexico. Environmental Management, v. 29, n. 2, p. 266-278, fev. 
2002. Disponível em: <http://link.springer.com/article/10.1007\%2Fs00267-001-0024-0?LI=true> . Acesso em: 12 mar. 2012.

FLORIANO, Eduardo P. Políticas de gestão ambiental. 3. ed. Santa Maria: Anorgs, 2007.

FONSECA, Jairo S.; MARTINS, Gilberto A. Curso de estatística. 6. ed. São Paulo: Atlas, 1996.

IPEA. Instituto de Pesquisas Econômicas Aplicadas. Sustentabilidade ambiental no Brasil: biodiversidade, economia e bem-estar humano. O uso do poder de compra para a melhoria do meio ambiente. Série eixos do desenvolvimento brasileiro. n. 82. Comunicados do Ipea, 2011. Disponível em: <www.ipea.gov.br/>. Acesso em: 10 jan. 2012.

JUSTEN FILHO, MARÇAL. Comentários à lei de licitações e contratos administrativos. São Paulo: Dialética, 2012.

KUNZLIK, Peter. Making the market work for the environment: acceptance of (some) 'green' contract award criteria in public procurement. Journal of Environmental Law, v. 15, n. 2, p. 175-201, jan. 2003.

LAMBERT, Yvan. Environmental and fishing limitations to the rebuilding of the northern Gulf of St. Lawrence cod stock. Canadian Journal of Fisheries \& Aquatic Sciences, v. 68, n. 4, p. 618-631, abr. 2011. Disponível em: <www.nrcresearchpress.com/journal/cjfas>. Acesso em: 10 jan. 2012.

MARRON, Donald. Greener public purchasing as an environmental policy instrument. In: OECD. The environmental performance of public procurement. Issues of policy coherence. France: OECD Publications, 2003.

MARX, Angela M.; PAULA, Istefani C. de; SUM, Fabiane. Sustainable consumption in Brazil: identification of preliminary requirements to guide product development and the definition of public policies. Natural Resources Forum, v. 34, n. 1, p. 51-62, fev. 2010. Disponível em: < http://onlinelibrary.wiley.com/doi/10.1111/j.1477-8947.2010.01293.x/abstract>. Acesso em: 2 mar. 2012.

MENEGUZZI , Rosa M. Conceito de licitação sustentável. In: SANTOS, Murillo; BARKI, Teresa V. P. (Coord.). Licitações e contratações públicas sustentáveis. Belo Horizonte: Fórum, 2011. p. 19-36.

MOTA, Carlos P. C. Eficácia nas licitações e contratos. Belo Horizonte: Del Rey, 2005.

MPOG. Ministério do Planejamento, Orçamento e Gestão. Instrução Normativa n⿳丷o 01, de 19 de janeiro de 2010. Dispõe sobre os critérios de sustentabilidade ambiental na aquisição de bens, contratação de serviços ou obras pela Administração Pública Federal direta, autárquica e fundacional e dá outras providências. DOU Seção I, n. 13, de 20 de janeiro de 2010. Disponível em:<http://portal.in.gov. br>. Acesso em: 15 out. 2010.

MPOG. Ministério do Planejamento, Orçamento e Gestão. Portal de compras do governo federal comprasnet. Disponível em:<http://comprasnet.gov.br>. Acesso em: 30 jul. 2012.

MPOG. Ministério do Planejamento, Orçamento e Gestão; ICLEI. Governos Locais pela Sustentabilidade. Guia de compras públicas sustentáveis para a administração federal. Brasília, 2009. Disponível em: <http://cpsustentaveis.planejamento.gov.br/wp-content/uploads/2010/06/Cartilha.pdf>. Acesso em: 15 mar. 2011. 
MURRAY, J. Gordon. Improving the validity of public procurement research. International Journal of Public Sector Management, v. 22, n. 2, p. 91-103, mar. 2009. Disponível em: <http://dx.doi. org/10.1108/09513550910934501>. Acesso em: 12 maio 2012.

ONU. Organização das Nações Unidas. Agenda 21 - Programme of action for sustainable development. Nova York: Nações Unidas, 1992. Disponível em: <www.un.org/esa/dsd/agenda21/>. Acesso em: 7 dez. 2010.

OZGUL, Arpat et al. Dynamics of body mass and population growth in response to environmental change. Nature, n. 466, p. 482-485, jul. 2010. Disponível em: <www.nature.com>. Acesso em: 12 mar. 2012.

PALMUJOKI, Antti; PARIKKA-ALHOLA, Katriina; EKROOS, Ari. Green public procurement: analysis on the use of environmental criteria in contracts. Reciel - Review of European Community \& International Environmental Law, Oxford, v. 19, n. 2, p. 250-262, out. 2010. Disponível em: <http:// onlinelibrary.wiley.com/journal/10.1111/(ISSN)1467-9388>. Acesso em: 12 fev. 2012.

PNUD. Programa das Nações Unidas para o Desenvolvimento. Relatório do desenvolvimento humano 2011. Disponível em: <http://hdr.undp.org/en/media/HDR_2011_PT_Complete.pdf >. Acesso em: 15 mar. 2011.

PNUMA. Programa das Nações Unidas para o Meio Ambiente. Rumo ao consumo sustentável na América Latina e Caribe. Publicação de base para o Workshop sobre Consumo Sustentável na América Latina e Caribe. São Paulo: Nações Unidas, 2001. Disponível em: <www.pnuma.org/eficienciarecursos/documentos/conslacp.pdf > . Acesso em: 15 mar. 2011.

PORTILHO, Fátima. Consumo sustentável: limites e possibilidades de ambientalização e politização das práticas de consumo. Cad. EBAPE.BR, Rio de Janeiro, v. 3, n. 3, p. 1-12, 2005. Disponível em: $<$ http://app.ebape.fgv.br/cadernosebape/asp/dsp_lst_artigos_edicao.asp?coded =30>. Acesso em: dez. 2011.

PORTILHO, Fátima; RUSSO, Fátima F. Processo Marrakech — o consumo sustentável visto pelos organismos internacionais. In: ENCONTRO NACIONAL DA ANPPAS, IV, 2008, Brasília. Anais eletrônicos... Brasília: Associação Nacional de Pós-Graduação e Pesquisa em Ambiente e Sociedade, 2008. Disponível em:<www.anppas.org.br/encontro4/cd/ARQUIVOS/GT13-413-412-20080510231242. pdf $>$. Acesso em: 12 jan. 2011.

RAO, Purba; HOLT, Diane. Do green supply chains lead to competitiveness and economic performance? International Journal of Operations \& Production Management, v. 25, n. 9, p. 898-916, set. 2005.

SACHS, Ignacy. Desenvolvimento includente, sustentável, sustentado. Rio de Janeiro: Garamond, 2008.

SANTOS, Fabrício V. A legalidade das compras públicas sustentáveis. Jus Navigandi, Teresina, v. 16, n. 2774, fev. 2011. Disponível em: <http://jus.uol.com.br/revista/texto/18421>. Acesso em: 17 abr. 2011.

SIENA, Osmar. Método para avaliar progresso em direção ao desenvolvimento sustentável. Tese (doutorado) - Programa de Pós-Graduação em Engenharia de Produção, Universidade Federal de Santa Catarina, Florianópolis, 2002. 
STEVENS, Candice. Linking sustainable consumption and production: the government role. Natural Resources Fórum, v. 34, n. 1, p. 16-23, fev. 2010. Disponível em: <http://onlinelibrary.wiley.com/ doi/10.1111/j.1477-8947.2010.01273.x/abstract>. Acesso em: 8 mar. 2012.

VALENTE, Manoel A. L. Marco legal das licitações e compras sustentáveis na administração pública. Consultoria legislativa. Brasília: Biblioteca da Câmara dos Deputados, 2011. Disponível em: $<$ www2.camara.leg.br/documentos-e-pesquisa/publicacoes/estnottec/tema1/2011_1723.pdf $>$. Acesso em: 10 jun. 2013.

VEIGA, José E. Desenvolvimento sustentável: o desafio do século XXI. Rio de Janeiro: Garamond, 2005.

Maria Alice Cruz Alencastro é bacharel em direito e doutoranda em desenvolvimento e meio ambiente pela Universidade Federal do Ceará (UFC). E-mail: alicealencastro@yahoo.com.br.

Edson Vicente da Silva é doutor em geografia. Professor do Departamento de Geografia da Universidade Federal do Ceará (UFC). E-mail: cacau@ufc.br.

Ana Maria D’Ávila Lopes é professora do Programa de Pós-graduação em Direito da Universidade de Fortaleza (Unifor). E-mail: anadavilalopes@yahoo.com.br. 
